\title{
Sorghum polyphenols: plant stress, human health benefits, and industrial applications
}

\author{
Pummy Kumari $^{1}$ [ $\cdot$ Vinod Kumar $^{2} \cdot$ Rakesh Kumar $^{3} \cdot$ Surender Kumar Pahuja ${ }^{1}$ \\ Received: 8 February 2021 / Accepted: 3 August 2021 / Published online: 10 August 2021 \\ (c) The Author(s), under exclusive licence to Springer-Verlag GmbH Germany, part of Springer Nature 2021
}

\begin{abstract}
Main conclusion Various phenolic compounds of sorghum are effective in the manag nen ab: otic stress (salt, nutrients) and biotic stress (caused by birds, fungi and aphids). The health and induscria plication of phenolics is mainly contributed by inherent antioxidant and nutraceutical potential.
\end{abstract}

Abstract In a natural environment, plant growth is affected by various biotic ara iotic stry sses. In every ecosystem, the presence of a wide range of harmful biological agents (bacteria, fungi, nemato n no insects) and undesirable environmental factors (drought, salinity, heat, excessive or low rainfall, etc.) may cau heavy loss in crop productivity. Being sessile during evolution, plants have evolved multiple defense mechanism ninst vistious types of microbial pathogens and environmental stresses. A plant's natural defense system produces some dor 4 pu nds named secondary metabolites, which include phenolics, terpenes, and nitrogen. The phenolic profile of grain so ghum, the least utilized staple crop, is unique, more diverse, and more abundant than in any other common erea ain. It mainly contains phenolic acids, 3-deoxyanthocyanidins and condensed tannins. Sorghum polyphenols play najor ole in plant defense against biotic and abiotic stresses and have many additional health benefits along with var ous ind io applications. The objective of this review is to discuss the phenolic compounds derived from grain sorghun d lescribe their role in plant defense, human health, and industrial applications.

Keywords Sorghum $\cdot$ Phenolics $\cdot$ Antioxid 'ht $\cdot$ Abl stress $\cdot$ Animal feed

\section{Introduction}

Phenolics are the largest group of Becondary metabolites in plants. They vary in hap from simpler aromatic rings to more complex ones, onins. All these phenolic compounds origin te from $\mathrm{p}$ zylalanine; therefore, they are also called phe ylp anoids. These phenols are synthesized

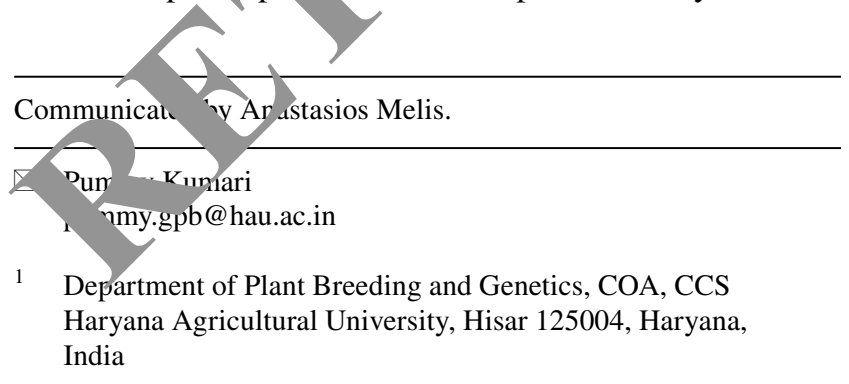

2 Department of Biochemistry, COBS\&H, CCS Haryana Agricultural University, Hisar 125004, Haryana, India

3 Department of Microbiology, COBS\&H, CCS Haryana Agricultural University, Hisar 125004, Haryana, India by the phenylpropanoid pathway and are divided into several groups, such as phenolic acids, flavonoids, hydrolysable tannins, monolignols, stilbenes, and lignans, each with peculiar properties. Various phenolic compounds play an important role in the acclimatization of plants to unfavorable environmental conditions (Barcelos et al. 2016). The concentration of phenolic compounds in plant tissue is a good indicator for predicting the extent of abiotic stress tolerance in plants. It varies significantly in different plant species under an array of external factors, such as drought, heat, and cold. The growth and development, including seed germination, biomass accumulation, and metabolism of plants, are also influenced by plant phenolics. In this review, different types of sorghum phenolic compounds and their beneficial role in plant stress management, human health, and related industries have been discussed. 


\section{Sorghum grain and its nutritional composition}

The $\mathrm{C}_{4}$ cereal sorghum grain is rich in polysaccharides (starch and non-starch), followed by proteins and lipids. The genetic characteristics of the cultivar, soil type, and environmental conditions during the season have a major impact on the content and composition of starch, i.e., the main polysaccharides in the grain. Sorghum has the lowest starch digestibility among cereals due to the strong association between the starch granules, proteins, and tannins (Mkandawire et al. 2013). Prolamins are major sorghum proteins with an average of $77-82 \%$ of the total proteins, and the remainder is albumins, globulins, and glutelins. The kafirins are the major prolamins of the sorghum and comprise three major classes: $\alpha$-kafirins (66-84\%), $\beta$-kafirins (8-13\%), and $\gamma$-kafirins (9-21\%) (Mokrane et al. 2010). Overall, the digestibility of sorghum proteins, especially after cooking, is lower than other cereals, such as wheat and maize. The main reason for the low digestibility of sorghum proteins is the resistance of kafirins to peptidase due to the formation of intramolecular disulfide bonds (Belton et al. 2006). Regarding the lipid profile of sorghum, it is $1.24-3.07 \mathrm{~g} / 100 \mathrm{~g}$ of grain weight and mainly composed of unsaturated fatty acids. The primary fatty acids of sorghum are linoleic acid, oleic acid, palmitic acid, and linolenic acids. In most of the varieties of ghum, the polyunsaturated fatty acids (PUFA) are 1 oher in content than monounsaturated fatty acids MU (Mehmood et al. 2008). The sorghum genotyp have bec studied elsewhere for various quality paramuters umari et al. 2016, 2017; Laxmi et al. 2019; Crakraborthy, et al. 2020).

Sorghum is a source of various min $1 \mathrm{~s}$, sv $\mathrm{ch}$ as phosphorus, potassium, and zinc, wh contents vary according to cultivation. Although the con it is known, the bioavailability of most 2 minerals from sorghum is scarcely known. The $b$, vai ility of zinc varies between $9.7 \%$ and $17.1 \%$, a d for anges from 6.6 to $15.7 \%$. Currently, effo is e being made worldwide to enhance the content no bioa ilability of iron and zinc through biofortif ation, fortifcation, and genetic improvement of sorghu ' Krug $r$ et al. 2013). India's first biofortified varict. ff sor am, ICSR 14,001 with its higher iron and 2 voyeloped by ICRISAT and released as 'Parbhan 'akti' for cultivation by Vasantrao Naik Marathwada Krishi) Vidyapeeth (VNMKV), Maharastra.

\section{Sorghum polyphenols}

Phenolics are broadly distributed in the plant kingdom and are found abundantly as secondary metabolites of plants. Plant polyphenols have drawn increasing attention due to their potent applications in various fields (Dai and Mumper 2010). During the last decade, sorghum has attracted great attention from the food, feed, fod $/$ er and drug industries due to its unique phenolic prof le, which helps it combat environmental stresses, such as acan! abiotic stresses, along with its multifold human hea benefits, including reducing oxidative stres nd car cer prevention (Yang et al. 2009). The pb-nolic p fil of grain sorghum is more diverse than 1 ose observed in other cereals, such as wheat, barle', ri maize, rye, and oats. Phenolic acids, condensed tà ins, ravonoids, stilbenes, and lignins are the ma r pheno spresent in grain sorghum and are produ ed the phenylpropanoid pathway. Among these phe-lic acids Yavonoids (3-deoxyanthocyanidins), and nde sed tannins are higher proportionally and biologicalls ore active. The phenolics in sorghum grain are oncentra $\mathfrak{d}$ in the bran layer, and their content, concentra 10. extractability vary greatly amongst sorghum varicies and genotypes (Ofosu et al. 2021). As the I olic profile in sorghum is strongly associated with its bioa ive properties, the knowledge of the phenolic strucre, composition, location (that is, bran and kernel) and fo, $n$ of presence (that is, free and bound) in sorghum grain is crucial for the extraction method, material selection, and processing design, and thus, it is tailored for specific needs. Xiong et al. 2021 studied cellular antioxidant activity of sorghum phenolic extracts and reported that colored bran like brown and black sorghum has great potential to be used as a natural antioxidant for food and nutraceutical applications. The identification and development of phenolic compounds or extracts from plants have become a major area of health or related research (Dai and Mumper 2010). An overview of different types of sorghum phenolics is given in the following sections.

\section{Phenolic acids}

According to their structure, phenolic acids can be divided into two categories: hydroxybenzoic acid and hydroxycinnamic acid (Kumar and Goel 2019). The total concentration of phenolic acids in sorghum grain is in the range of 445-2850 $\mu \mathrm{g} / \mathrm{g}$ (Girard and Awika 2018). These acids exhibit high antioxidant activity in vitro and thus have human health benefits (Kamath et al. 2004). The contents of primary phenolic acids based on studies of some sorghum varieties are provided in Table 1. 
Table 1 Concentration of various phenolic acids in sorghum grain

\begin{tabular}{ll}
\hline Phenolic acids & $\begin{array}{l}\text { Conc. in } \\
\text { sorghum grain } \\
\mathrm{mg} / \mathrm{g}\end{array}$ \\
\hline Protocatechuic acid & $150.3-178.2$ \\
Ferulic acid & $120.5-173.5$ \\
p-coumaric acid & $41.9-71.9$ \\
Syringic acid & $15.7-17.5$ \\
Vanillic acid & $15.4-23.4$ \\
Gallic acid & $14.8-21.5$ \\
Caffeic acid & $13.6-20.8$ \\
Cinnamic acid & $9.8-15.0$ \\
Hydroxybenzoic acids & $6.1-16.4$ \\
\hline
\end{tabular}

Modified from Afify et al. (2012)

These phenolic acids occur in a bound state and have decreased bioavailability. They are not hydrolyzed by human digestive enzymes but are fermented by the colon's microbiota (Hole et al. 2012). The phenolic compounds of wines, fruits, and vegetables have a good bioavailability compared to the phenolic acids of cereals, including sorghum, because they are mostly bound to arabinoxylans chains or lignin (Abdel-Aal et al. 2012). Descriptive knowledge about techniques for improving the bioavailability of phenolic acids in sorghum is incipient. Therefore, microorganisms and groin processing play a key role in improving their bioava ability (Salazar-López et al. 2018). Cereal fermentation $n$ specific probiotic strains and cooking processe, an signı cantly increase the contents of free phenolic icia hereby improving their bioavailability in sorghy (Saura-y Mixto et al. 2010; N'Dri et al. 2013).

\section{Tannin}

Grain sorghum contains nins with a high molecular weight and has a high ore of noymerization compared to other cereals, ar the, re the most investigated polyphenols in sorg $\mu$ The ta $\mathrm{sin}$ content varies from 10.0 to $68.0 \mathrm{mg} / \mathrm{g}$ dry wt. tannin sorghum compared to other cereals and pulses (Tannin-free sorghum at $0.5-3.8 \mathrm{mg} / \mathrm{g}$, Finger millet at $3.6-13.1 \mathrm{mg} / \mathrm{g}$, Buckwheat groats at $1.7 \mathrm{mg} / \mathrm{g}$, and Cowpea at $1.8-2.9 \mathrm{mg} / \mathrm{g}$ ) (Awika 2000). The concentration of tannin in sorghum cultivars, in relation to their color, varies significantly, for example, red and brown grain sorghums contain more bioactive compounds, such as tannins, which are considered beneficial to human health and are widely used in the beer and food industry (Eastin and Lee 2020). Based on tannin concentration and its extractability, sorghums can be classified into three types 0 not a', 2019). Type I sorghums with no pigmented testa th have negligible or shallow levels of tannins $1.8 \mathrm{mg}$ CAE/g). Type II sorghums have pigmented testuwit. nod rate levels of tannins and are extractable with acidit, d methanol (6.4-15.5 mg CAE/g). Type JI st hums have pigmented testa with a high tannin conce. are found mainly in the tr sta cell 1ls and the pericarp, and are extractable by $m$ tha 1 or acidified methanol (Dykes and Rooney 2006) In geno //sorghums with pigmented testa have high ever of condensed tannin content, and Type III sorghums co ir w. ost a ten times higher tannin concentration than oth tannin-containing cereals (Girard and Awika 20

Despite the anti-nutritional effect, tannins have been ansively, fudied and used for human health-promoting cap. lities because tannins are 15-30 times more effecve $t$ an simple phenolics in radical scavenging ability. 1. functional benefits of sorghum are attributed mainly to Jigomers, which have been extensively studied (Beecher 2004). The oligomers of tannins in foods contribute up to $19 \%$ of the antioxidant capacity of the diet, which benefits human health and promotes the prevention of non-communicable diseases due to immunomodulatory, anticancer, antioxidant, antiradical, anti-inflammatory, vasodilatory, cardio-protective, antithrombotic and anti-UV actions (Floegel et al. 2010).

The high tannin concentration in sorghum also offers an agronomical advantage over low tannin cultivars because the former protects the plants against pathogen and bird damage and can be grown in some under-developed regions of the world that have food security issues (Table 2) (Kil et al.

$\begin{array}{lllllll}\text { Type I sorghums } & \text { White } & \text { White } & \text { No } & \text { Tannin conc } & \text { Phenolic profile } & \begin{array}{l}\text { Resistance to mold } \\ \text { and bird attack }\end{array} \\ & \text { Yellow } & \text { Yellow } & \text { No } & \text { No } & \text { Very low } & \text { Low resistance } \\ & \text { Red } & \text { Red } & \text { No } & \text { No } & \text { Low } & \text { Low resistance } \\ \text { grain color }\end{array}$

Modified from Audilakshmi et al. (1999); Xiong et al. (2019) 
2009). The grain mold resistance of the genotype is significantly improved by a darker glume color, higher content of phenols, and the hardness of the seed (Audilakshmi et al. 1999). Recently, a known SNP (S4_62316425) in the TAN1 gene, a regulator of tannin accumulation in sorghum grain, was detected with a significant association with grain mold resistance (Nida et al. 2021), as the processing of phenolic acids improves the digestibility of tannins in sorghum. The processing of grain sorghum in dry heat $\left(95^{\circ} \mathrm{C}\right.$ for $20 \mathrm{~min}$ and $121{ }^{\circ} \mathrm{C}$ for $30 \mathrm{~min}$ ) can depolymerize the condensed tannins in sorghum (Barros et al. 2012), which can increase their bioavailability. Thermal processing is one strategy to increase the bioavailability of tannins with a minimum reduction in the content of these compounds. Thus, the functional potential of tannins-rich sorghum can be maintained or even increased. Furthermore, the reduction of polymeric tannins may boost the digestibility of starch and proteins, increasing the nutritional value of the grains. The depolymerization of tannins through other types of processing needs to be studied.

\section{Flavonoids}

Most flavonoids of the sorghum are located in the bran layers of the grain. The concentration of flavonoids is largely affected by the color and thickness of the pericarp and the presence of the testa (Dykes et al. 2011). Anthocyanins, $\mathrm{f}_{\mathrm{q}}$ vones, and flavanones are major flavonoids that are $\mathrm{p}^{\mathrm{s}}$ sent in the sorghum grain. Sorghum anthocyanins belong class of 3-deoxyanthocyanidins and correspo t to up . $79 \%$ of the sorghum flavonoid content (Dyk s an Pooney 2006). Due to the absence of a hydroxy' group at p ition C-3 in 3-deoxyanthocyanidins, they a e more stable than other anthocyanins (Taleon et al. 2012)

The content of sorghum 3-de rvanthocyanidins correlates with its color and antioxidalt a.y (Kayodé et al. 2011). Varieties with blacl icarp and testa have 3-4 times more total 3-deoxyant ya dins $(5.4-6.1 \mathrm{mg} / \mathrm{g})$ than red and brown varieties (1.0 $8 \mathrm{mg} / \mathrm{g}$ ) (Awika et al. 2004).

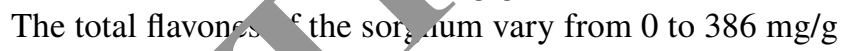
(on average, $8>\mathrm{mg} / \mathrm{c}$ The lowest content of flavonoids is found in vite pericary varieties, and the highest contents are obser the emon-yellow pericarp (474-1780 mg/g)

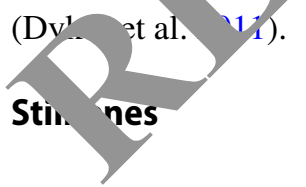

Stilbenes belong to a small family of phenolic compounds derived from the phenylpropanoid pathway (Chong et al. 2009). They have numerous implications in plant disease resistance and human health. Stilbene content has a positive correlation with grain color and is present in smaller quantities in white-colored varieties. White sorghum contains traces of trans-piceid (up to $0.1 \mathrm{mg} / \mathrm{kg}$ ) but lacks trans-resveratrol, whereas red sorghum has both (Bröhan et al. 2011). Stilbene compounds, a diverse group of natural defense phenolics, which are abundant in grapes, berries, sorghum, and conifer bark waste, may also confer a protective effect against aging-related diseases (Reinisalo et al. 2015).

\section{Sorghum phenolics: applications in biotic and abiotic stress management}

In the twenty-first century, to meet the f dema)d of the fast-growing human population, we ned nhonce crop productivity and minimize crop 1 sses. How, ver, several biotic and abiotic stresses (insect $\mathrm{p}$ attack foliar and grain disease, drought, salinity, cor heat, avy metal toxicity, UV radiation, etc.), inc reased balization and anthropogenic activities an 1 ced climate changes are badly affecting a large proportion f/arable land. These abiotic stresses affect lant, rowth and result in poor yield due to alteration in $\mathrm{ph}_{\text {. }}$ ory al and biochemical processes of plants (Wani et al. 5 ). Plants exhibiting increased synthesis of polyp. $\quad{ }^{1}$ c under biotic and abiotic stresses usually show bette adaptability to limiting environments (Sharma 1 2019).
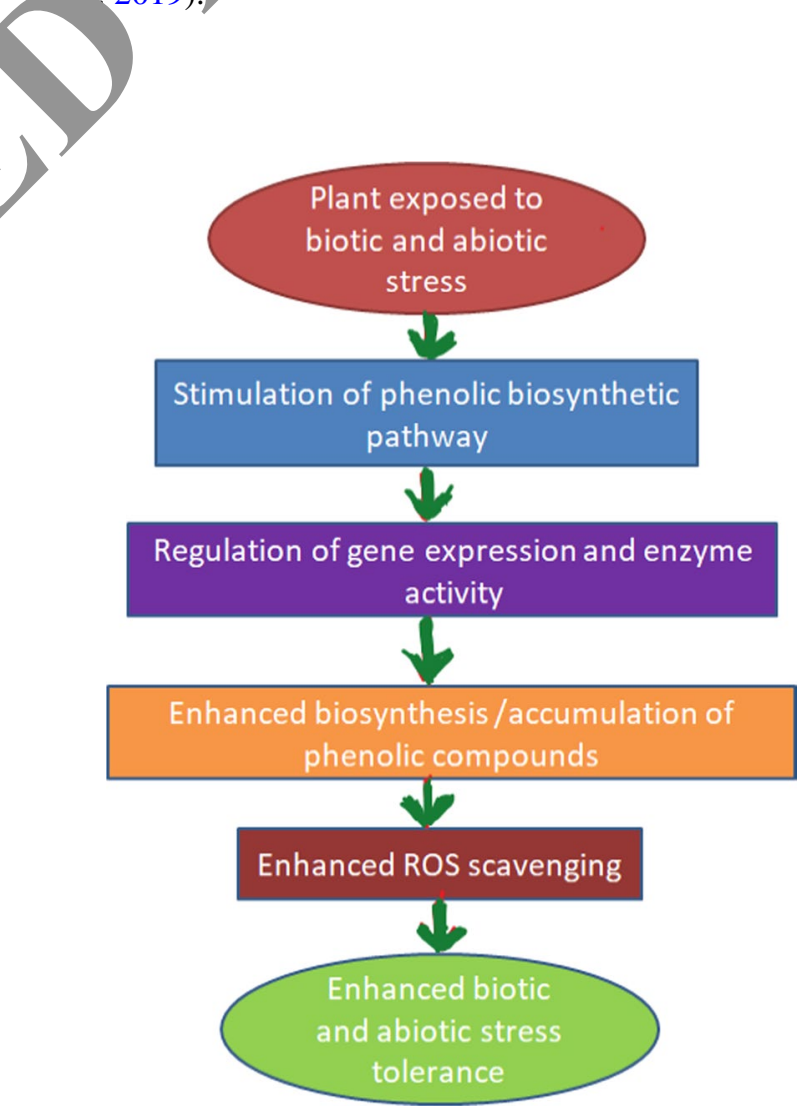

Fig. 1 Mechanism of how phenolics help towards biotic and abiotic resistance 
Sorghum's ability to thrive under both biotic and abiotic stressors is mediated, in part, through the diverse families of secondary metabolites synthesized by a plant (Fig. 1). Sorghum possesses a variety of phytochemicals that are potentially helpful in overcoming the biotic and abiotic stresses in a plant. Various sorghum phenolic compounds, viz. phytoalexins (3-deoxyanthocyanidins) or allelochemicals (p-hydroxybenzoates, p-coumarates, and flavanols), play important roles in providing resistance for plants against biotic and abiotic stresses (Weir et al. 2004). Walling (2008) reported that some aphids are thought to have developed tolerance mechanisms against certain secondary metabolites. Interestingly, flavonoids have been suggested as candidate compounds that confer resistance to aphids in sorghum and other plant species (Kariyat et al. 2017). The genotypes accumulating higher levels of the cyanogenic glucoside (dhurrin) are resistant to aphids (Dreyer and Jones 1981) and the southwestern corn borer (Cheng et al. 2013). Many phenylpropanoids, phenolic acids, flavonoids, and condensed tannins have been implicated in plant resistance, with 3-deoxyanthocyanidins being the prominent ones (Deng and Lu 2017). Dicko et al. (2005) studied the relation between different phenolic compounds and biotic stresses (sooty stripe, sorghum midge, leaf anthracnose, striga and grain molds) and abiotic stress (lodging, drought resistance and photoperiod sensitivity) management and observed that sorghum varieties that have resistance to biotic and abiotic stresses had on av rage higher contents of 3-deoxyanthocyanidins (3-DAs), $\mathrm{p}_{\text {. }}$ thocyanidins (PAs) and flavan-4-ols compared suscep. ble varieties (Fig. 2). The contents of 3-DAs and s were suggested to be a good marker for resiscance of so num to both biotic and abiotic stresses bec use these correlate with resistance to all stresses except $f$ vhotor/eriod sensitivity in grain sorghum.

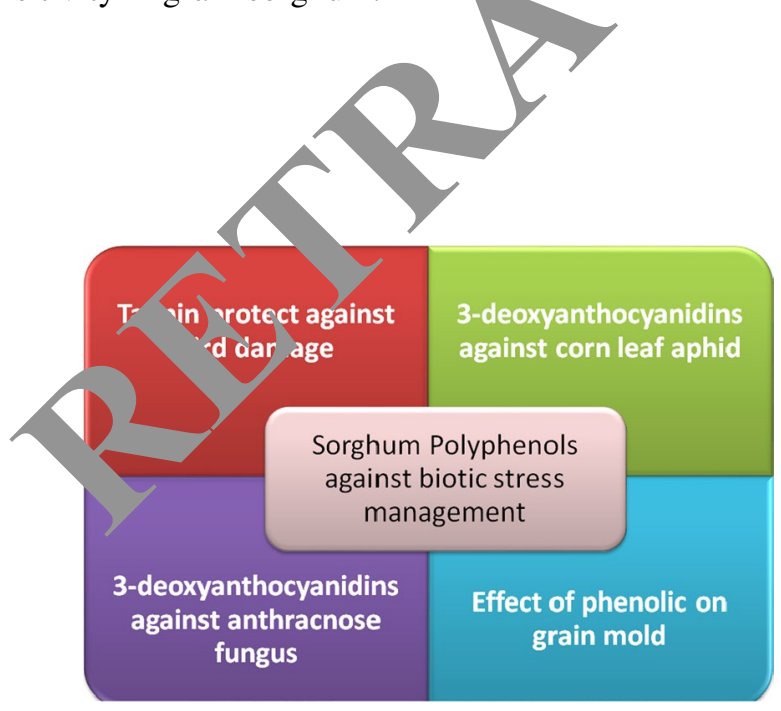

Fig. 2 Sorghum polyphenols effective against major biotic stresses

\section{Tannins: role in protection against bird damage}

Bird damage is one of the most severe biotic constraints on crop production worldwide (De Mey et al. 2012; Anderson et al. 2013). Some cereal crops, such as wheat, rice, rye, sorghum, and millets, are more vulnerable to bird damage by lodging, pecking seeds and sucking the juice from immature seeds, preventing the full develepment of many grains and frequently encouraging man other plant diseases around panicles (Tipton et al. 770 ). Dixon et al. (2005) reported that the in ased levels of condensed tannins (widely known as proa ocyanidins; PAs) in sorghum varieties also ffect the sp arrow feeding behavior. Based on GWAS a lysis of a large-scale sorghum germplasm diversi, ane, nie and Xu (2019) revealed that Tannin1 a codes a 10 protein functioning in the WD40/M Y B , YLH complex, which controls bird feeding beharior in so hum. The study of sparrow feeding and sr rro attractant volatile assays confirmed the anti-feedan a a am -attractant functions of differentially acmumulate Ketabolites on bird behavior. Birdpreference a. possess a variety of aromatic and fatty acid-rerived volatile accumulation at significantly her levels.

\section{Deoxyanthocyanidins: effectiveness against anthracnose fungus}

In Sorghum, a group of phytoalexins is induced at the infection site by Colletotrichum sublineolum, the anthracnose fungus. These compounds, classified as 3-deoxyanthocyanidins, have structural similarities to the precursors of phlobaphenes. 3-Deoxyanthocyanidins were detected as major flavonoids in black sorghum grains (Taleon et al. 2012). The contribution of flavonoid phytoalexins in resistance against Colletotrichum sublineolum in sorghum has been investigated by comparing the response of several sorghum cultivars that differentially produce 3-deoxyanthocyanidins (Basavaraju et al. 2009). Loeh et al. (1999) reported that sorghum responds to the invasion of both pathogenic and nonpathogenic fungi by the induction of 3deoxyanthocyanidin phytoalexins. Ibraheem et al. (2010) carried out an experiment by using yellow seed sorghum to study the effect of flavonoids on anthracnose leaf blight. It was reported that sorghum yellow seed $1(y l)$ encodes a MYB transcription factor, which regulates phlobaphenes biosynthesis and its near-isogenic lines, but having lossof-function alleles of $y 1$ means that it is not able to accumulate phlobaphenes. Molecular characterization of the 
two null $y l$ alleles shows a partial internal deletion in the $y 1$ sequence. These null alleles, designated as $y l-w w l$ and $y 1-w w 4$, do not accumulate 3-deoxyanthocyanidins when challenged with the nonpathogenic fungus Cochliobolus heterostrophus.

Furthermore, compared to the wild-type allele, both $y 1$ $w w 1$ and $y l-w w 4$ show greater susceptibility to the pathogenic fungus $C$. sublineolum. In fungal-inoculated wildtype seedlings, $y l$ and its target flavonoid structural genes were coordinately expressed. However, in $y 1-w w 1$ and $y 1$-ww4 seedlings, where $y 1$ was not expressed, steadystate transcripts of its target genes were not detected. Cosegregation analysis showed that the functional yl gene is genetically linked with resistance to $C$. sublineolum. In conclusion, a significant reduction in ALB disease symptoms was reported with a higher accumulation of known 3-deoxyanthocyanidins in sorghum plants carrying a functional $y l$ allele in response to infection by the anthracnose fungus C. sublineolum. In Sorghum bicolor metabolomic analysis of defense-related reprogramming in response to Colletotrichum sublineolum infection, it also revealed a functional metabolic web of phenylpropanoid and flavonoid pathways (Tugizimana et al. 2019).

\section{Deoxyanthocyanidins: defense against corn leaf aphid}

Sorghum is also a potential host to more thar 150 inse pests with aphids being a major group of tem Tharmá 1993). Almost four species of aphids fee 1 orr sorght. and corn leaf aphid (CLA) Rhopalosiphu (Hemiptera, Aphididae) is the majo ne anlong them (Young and Teetes 1977). To d cand aganst any damaging pests, plants have evolved a spe defense mechanism that is mainly class into physical and chemical defenses. Among the hys al de enses, leaf trichomes and epicuticular wa ha been suggested to play a significant role ag? many $\mathrm{h}$ rbivorous species, including aphids (Eigenbiode. Espelie 1995; Kariyat et al. 2017). Insect her'1vory elicits complex counter defense responses from plan alud ing the biosynthesis of toxic secondary met ites a act as chemical defense against particular j cti he sueh as glycosides, alkaloids, benzoxazinoids, glu i inolates, and flavonoids (Betsiashvili et al. 2015). For exc, nple, vanillic and aconitic acids have been found to have antifeedant properties, and sorghum genotypes with higher polyphenol contents are less preferred by aphids (Mote and Shahane 1993). In sorghum, the $y l$-regulated flavonoid pathways have resulted in deleterious effects on aphids, resulting in defense against corn leaf aphid (Kariyat et al. 2017).

\section{Phenolics: effect on grain mold}

'Grain mold' is a significant biotic stress affecting the production, marketing, and productivity of grain sorghum. The term is used to describe the diseased appearance of sorghum grain resulting from infection of one or more pathogenic or saprophytic fungus. Funguses of more than 40 genera are associated with sorghum grain (Williams and Rao 1981). Most are restricted to the pericarp, but $p$ netration to endosperm occurs if the mature grain is expos a hig'? humidity for a longer period at maturity. Audilaksh al. (1999) studied sorghum genotypes for va. 'Is mol hological and biochemical traits and their contrib on o resistance for grain mold. Highly signifi ant correlat.ons between grain mold and seed hardnes $s, \mathrm{~s}$ phen plics content in acid methanol extract, and $\mathrm{g}_{1}$ con revealed that they strongly affected the gr in mol s sponse. Harder grain, higher levels of seed pho ls, and darker glumes contributed to grain mold-resistan Weaker and less consistent correlations w re o served between grain mold and seed color, seed flava +-or wntent, glume phenol, flavan-4-ol contents, and glun. Cover, indicating the relatively lower effect of thes ito on grain mold response. It has been suggested that ombinations of several attributes are required to eve effic,ent resistance (Audilakshmi et al. 1999). Esele (19) reported that a pigmented testa, where condensed nni s are present, is the most critical trait for conferring gr $n$ mold resistance. Red pericarp containing flavan-4-ol also plays a role in mold resistance but is not as effective as the pigmented testa. However, the combination of both provides additive effects on resistance. Melake-Berhan et al. (1996) also reported the same results, highlighting the correlation between tannin and flavan-4-ol with resistance in colored pericarp sorghums with pigmented testa. Not all red pericarp needs to be resistant to grain mold.

\section{Flavonoids and their role in salt stress management in sweet sorghum}

Abiotic stresses affect crop production and productivity worldwide. Plants have developed specific defense mechanisms against environmental stresses by altering the gene expression pattern, leading to the regulation of specific metabolic and defensive pathways. Sorghum is an essential crop in regions that are mainly irrigated by salty water. Sweet sorghum is a variant of common grain sorghum and is relatively more adapted to marginal growing conditions. Some phenolics, like anthocyanin and tannins, have a high antioxidant capacity and help in plant defense naturally against abiotic stresses, pests, and disease damage (Dempsey et al. 2011). 
Meng et al. (2015) reported that flavonoids have critical physiological roles in plants; their accumulation is induced by abiotic stresses and is a hallmark of plant stress. In addition, it has been observed that salt-tolerant species often accumulate more flavonoids than salt-sensitive species, which suggest a relationship between flavonoid biosynthesis and salt stress resistance (Liu and Godwin 2012). The high flavonoid contents may have contributed to elevating the antioxidant activity of the plant tissues under stress. The flavonoid biosynthesis pathway played an essential role in the high salt tolerance in the sweet sorghum landraces, and six genes involved in the flavonoid biosynthesis pathway to tannins and anthocyanins from phenylalanine have been identified in the sweet sorghum landraces. Moreover, their expression was observed to be significantly different from that in grain sorghum, based on RNA-Seq (Genzeng et al. 2019). The study revealed that the accumulation of tannin positively relates to the sorghum salt-resistance and flavonoids biosynthesis, which plays a vital role in the sweet sorghum capacity for salt tolerance.

\section{Phenolics and their impact on nutrient uptake in sorghum}

Despite their role in biotic and abiotic stress management, phenolics also improve nutrient uptake through che atien of metallic ions, enhanced active absorption sites an porosity which accelerate the mobilization of ele ents, suc as calcium $(\mathrm{Ca})$, magnesium $(\mathrm{Mg})$, potassium $\mathrm{K})$, c $(\mathrm{Zn})$, iron $(\mathrm{Fe})$, and manganese $(\mathrm{Mn})$ (Senevirame and Ja) oinghearachchi 2003). Sorghum is a rich s urce of flavonoids, such as flavonols, flavonones, flavons, d anthocyanins, which are particularly abundant ' red anu olack sorghum grain (Dicko et al. 2005) but rare or at in other plants (Awika et al. 2004). Som rkers have reported that high plant density and inter opi -nractices reduced insect pest infestation in cowpe a (Mà et al. 2010). This was probably due to the exceso accumu ation of phenolic compounds in plants growing in $h$ systems.

Musa e al. (2011) sudied sorghum-cowpea intercropping undo reatm nt with chemical and bio fertilization, lead to en ned critical macro and micronutrients $(\mathrm{Ca}$, C $\mathrm{Mn}$. and $\mathrm{Fe}$ ) of sorghum seeds. Because both cowpea sorghum are the staple food in many of the semiarid tro, 1 cal regions, growing them in mixed culture may be the main source of natural antioxidants, and these types of practices must be tried in these areas. Although several studies have shown that stress affects the release of these compounds, further studies are required to assess the effects of flavonoid and anthocyanin compounds in the control of pests (insects, diseases, and weeds) in mixed culture systems.

\section{Sorghum phenolic compounds: potential human health applications}

Currently, consumers think about their health, healthy living, and health food even when it is at a high cost (Vyas et al. 2018; Chaudhary et al. 2021). Sorghum is a nutricereal that is composed of starch, proteins, unsaturated lipids, and some minerals and vitamins. Most grain sorghum varieties are a rich source of phenolic crmpounds and bioactive compounds, especially 3-deoxy tosy? nidins and tannins, which have a great bealth im $_{1}$ t on human gut microbiota and reduce para ters rlaced to obesity, oxidative stress, inflammation, dia tee, dyslipidemia, cancer and hypertension ( e Morais ardoso et al. 2017). In addition to direct inti idant fffects, the sorghum phenolic compounds at indu - ndogenous detoxifying enzymes (phase $\mathrm{J}$ enzymo that are responsible for converting the harmf $11 \mathrm{~h}$ tive oxygen or nitrogen species into nontoxic commounds, $/$ indirectly enhancing the human body $d$ fens mechanism against oxidative stress (Awika et al. 24 Uoúález-Montilla et al. 2012).

\section{- vpher óls against cancer}

Tost cancers originate from DNA damage caused by carc1 ogenic agents, such as toxins and mutagenics, that make ap reactive intermediates, such as reactive oxygen species (ROS), reactive nitrogen species (RNS), and other reactive electrophilic metabolites (Sharma and Verslues 2010). The carcinogen rate in humans is strongly dependent on the activities of phase I (cytochrome P-450) and II enzyme systems, which also remove endogenous and environmental carcinogens (Takabe et al. 2006).

3-Deoxyanthocyanidins, a sorghum phenolic compound, have a strong influence on the phase II enzyme activity, especially on the enzyme NADH: quinone oxidoreductase (NQO) activity. 3-Deoxyanthocyanidins are strong NQO inducers. Both 3-deoxyanthocyanidin standards and 3-deoxyanthocyanidin-rich sorghum extract have been reported to increase the NQO activity in some cancer cells in particular. The inducing capacity of 3-deoxyanthocyanidins on the phase II enzyme varied greatly with their structure and substitution, such as methoxylated substitution at the C-5 and C-7 positions, such as with 7-methoxyapigeninidin and 5,7-dimethoxyapigeninidin, and can significantly enhance the inducing effect on the NQO activity (Yang et al. 2009). Because black and red sorghums are rich in 3-deoxyanthocyanidins, they have strong inducing effects on NQO activity. Surprisingly, white pericarp sorghums with low 3-deoxyanthocyanidin 
content have significant inducing effects on the NQO, indicating the possible role of other bioactive compounds that must also be investigated. However, overall epidemiological evidence has suggested that sorghum has anticarcinogenic properties when consumed regularly in the diet (Jideani et al. 2014).

\section{Polyphenols against dyslipidemia and cardiovascular disease}

Dyslipidemia may be defined as increased levels of serum total cholesterol (TC), low-density lipoprotein cholesterol (LDL-C), triglycerides (TG), or decreased serum highdensity lipoprotein cholesterol (HDL-C) concentration. Dyslipidemia is an established risk factor for cardiovascular disease (CVD). Various epidemiological data indicate that whole grain consumption significantly lowers mortality from CVD (Anderson 2003). Animal studies also suggest that sorghum consumption promotes cardiovascular health better than other cereals. Klopfenstein and Owen (1981) reported a cholesterol-lowering effect of low-tannin sorghum grain when fed to guinea pigs at $58 \%$ of the diet. This effect was more significant than that produced by wheat, rolled oats, or pearl millet. In vitro and animal studies have shown that the lipidic and phenolic fractions from sorghum modulate parameters are related to dyslipidemia and the risk of cardiovascular disease (de Morais Cardoso et al. 2017). These benefits result from the action of phytosterols, policosanol and other phenolics of sorghum, which may modulate $a b$. tion, excretion, and synthesis of cholesterol.

Diet supplementation with sorghum lipis se ed the hepatic and plasma cholesterol of normo proemic ha sters (Hoi et al. 2009). The phytosterols are c ie of the major bioactive compounds from the sorghum $\mathrm{li}_{1}$ fraction that can inhibit cholesterol absorption. Th nhytosterors in the cereal brans are believed to contribute ber al effects. Other components of the whole $n$, in luding polyphenols and fiber, also play a role iv VI nrevertion. Sorghum is a significant source of phytosto "s and policosanols (Singh et al. 2003). The bene f f sorghu, 1 to cardiovascular health may not be limited to pos e effects on cholesterol. Lee and Pan (2003) deronstrated that dietary tannin-sorghum distillery residues 1 red $3-97 \%$ of hemoglobin-catalyzed oxidation inole $1 \mathrm{~d}$ in cultured mullet fish compared to that i. oyb on (13\%) and rice bran (78\%), respectively.

\section{Overcoming oxidative stress using phenolic compounds}

The chronic and excessive production of free radicals in the human body is crucial in the development of noncommunicable diseases (Lee et al. 2011). The activity of components isolated from sorghum against oxidative stress has been demonstrated in vitro by various workers. Moraes et al. (2012) reported that extracts from black or red sorghum, when used, produce functional benefits attributed to the phenolic compounds. Phenolic compounds isolated from sorghum regulate the expression of phase II enzymes, which play an important role in modulating the defense system against oxidative stress by continuously converting highly reactive electrophilic species (RES) into nontoxic and extractable metabolites (González-Montillac 1__al2 Varieties of black sorghum may exert greater effects $\quad \mathrm{N}, \mathrm{O}$ due to its rich profile and high content of deoxyànthocyanidins (Devi et al. 2011).

Sorghum is a rich source of ot er phytoch micals, pigmented or not, that acts synercisti lly witt/3-deoxyanthocyanidins and produce high 1 . cer n nity. The effects of sorghum on oxidative str ss in vi are not well known. The superoxide dismutase act $\mathrm{v}$ (SOD) increased in normolipidemic rats fed with black s rium bran (rich in 3-deoxyanthocyanidin tha been reported (Lewis et al. 2008). This increase $a_{1}$ ard o strictly related to the action of 3-deoxyanthocyan " ps present in the bran. Furthermore, white (ric henolic acids), brown (rich in tannins), or black (rich 3-deoxyanthocyanidins) sorghum brans supased the rutathione peroxidase activity (GPx). However, the rmolipidemic animals fed with whole red sorghum ad $l$ wer concentrations of thiobarbituric acid reactive subSt ces (TBARS) in their livers (Moraes et al. 2012).

\section{Anti-obesity and anti-inflammatory effects of phenolics}

Obesity is a pandemic correlated with various non-communicable diseases and characterized by chronic low-grade inflammation. Adipocytes and obesity play an essential role in inflammatory mediators that signal this process. The discovery that obesity itself results in an inflammatory state in metabolic tissues opened a research field that examines the inflammatory mechanisms in obesity (Greenberg and Obin 2006). This unique understanding allows a more precise understanding of the role of adipocytes in health and obesity and about how inflammatory mediators that act as signaling molecules in this process (Gregor and Hotamisligil 2011). Sorghum as a whole grain is an excellent food for people with obesity because sorghum endosperm contains high levels of resistance and relatively low starch digestibility (Barros et al. 2012).

A study on rats, pigs, rabbits, and poultry suggested that tannin-rich sorghum reduces undesirable weight gain in obesity in humans (Muriu et al. 2002). Barros et al. (2013) demonstrated that sorghum polymeric tannins naturally modify starch by interacting strongly with amylose and form 
resistant starch. Resistant starch cannot be digested in the small intestine and thus reaches the large intestine, delivering the health benefits of dietary fiber (Sánchez-Zapata et al. 2015). Furthermore, sorghum tannins can inhibit starch digestion by inhibiting saccharase and amylase enzymes (Mkandawire et al. 2013). In another study, tannin-rich sorghums were found to be more effective than those rich in 3-deoxyanthocyanidins in inhibiting hyaluronidase, a vital enzyme associated with inflammation (Bralley et al. 2008).

\section{Diabetes: hypoglycemic effect of phenolics}

The commonly known forms of diabetes are T1DM, T2DM, and gestational diabetes (GD). Diabetes becomes a highly challenging health problem and is progressively prevalent globally with an estimated 1.5 million deaths per year (Ogurtsova et al. 2017). India has the world's second-largest number of people with diabetes after China (Wedick et al. 2015). This is a lifelong condition characterized by hyperglycemia in which the body is unable to secrete enough insulin. After a meal, a diabetic patient's glucose level rises intensely and prompts a fall down as the body is unable to stock the extra glucose for later use. Kam et al. (2016) reported that the use of gluten-free whole grains, such as sorghum quinoa, buckwheat, and minor millets might maintain the role of beta cells. Kim and Park (2012) have reportad from animal studies that phenolic extracts of sorghum nodulate glucose metabolism in animals due to the actic of the phenolic compounds and exhibit a hypogly mic effe similar to glibenclamida, an antidiabetic med catı 'ısed in their control group.

\section{Industrial applications of -orghum phenolic compounds}

Currently, due to the ver environmental impacts on human health and g,owin. onsumer awareness for healthy eating, there hao en a gry at demand for foods or food ingredients that hav positive health impact. Thus, sorghum has recently attracted much attention in developed countries wits high nutritional value and may enhance rapi after cOVID-19 pandemic. Due to the diverse $r$ nol nrofile of sorghum and its diverse role in the food ind $\mathrm{v}$, its industrial application is discussed below.

\section{Sorghum phenols as nutraceuticals}

The use of sorghum phenolic compounds, especially tannins, for the development of functional foods and nutraceuticals is an innovative idea. First, Links et al. (2015) developed a nutraceutical by encapsulating sorghum-condensed tannins into kafirin microparticles that can withstand gastric digestion and have shown good anti-hyperglycemic effects both in vitro and in vivo (Links et al. 2015). Condensed tannins are strong gluten strengtheners, especially those with a large molecular weight and a high degree of polymerization, which are capable of forming extensive crosslinking with gluten proteins. Sorghum-condensed tannins have significantly increased dough and better viscosity and stability, thus improving food structural stability and quality. Sorghum-condensed tannin could be used a ,atur I ingredient to enhance the quality of gluten and enh functionality, suggesting its potential as multifunchonal ingredient in the food and biomedical ${ }^{\prime}$ dus $(\mathrm{Gi}$ ard et al. 2019).

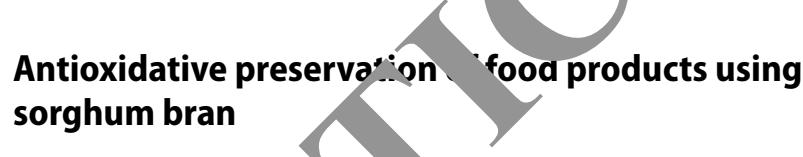

Apart from the e sorgh.m grain, sorghum bran also has a huge pe. tia the food industry. Sorghum bran is a high-value fun nal ingredient (Dykes 2019). The bran can be e ${ }^{1}$ obtal, ed by grain decortications and then used as a hatary colorant and antioxidant preservative in food products to improve food quality and preservation. For 1I. ce, Luckemeyer et al. (2016) reported that the addition of 0 . $-0.75 \%$ high-tannin sorghum bran to meat products, $\mathrm{h}$ as pre-cooked pork and turkey patties, was said to prevent lipid oxidation during storage without compromising the meat sensory flavor attributes. Similarly, Cabral et al. (2019) also noted that the addition of $0.5 \%$ high-tannin sorghum bran to pork pizza topping and dark chicken meat reduces lipid oxidation and rancid flavor. Although the addition of sorghum bran to meat products may also lead to a darker color and sorghum flavor, it does not necessarily indicate a poor meat quality or low consumer acceptance. Natural ingredients to improve food quality, safety, and health function while maintaining the sensory quality could be novel areas for future research.

\section{Production of gluten-free beers/beverages for Celiac people}

Sorghum provides the opportunity of producing gluten-free beers/beverages for celiac patients because it is a gluten-free cereal. Beer made of white sorghum has more than two times higher phenolic contents than barley beer, which contributes to its high antioxidant activity, and this beer also contains significant amounts of $\gamma$-aminobutyric acids with potential antihypertensive activity; it also has $\alpha$-glucosidase inhibitory activity and low ethanol content. Consumption of this beer could promote human health if consumed in moderation by Celiac patients (Garzón et al. 2019). 


\section{Gluten-free cookies and biscuits for diabetics}

Sorghum can be used to make gluten-free healthy snacks, such as cookies and biscuits for diabetics. Cookies made from tannin sorghum grain have been shown to have high phenolic contents and antioxidant activity, especially those with an antioxidant activity up to 20 times higher than wheat cookies (Chiremba et al. 2009). However, tannin sorghum cookies have low sensory acceptance despite their high antioxidant activity and great health properties. Thus, the production of nontannin sorghum cookies has great potential for commercialization and large-scale production. They have similar sensory acceptance as wheat cookies, with the phenolic contents and antioxidant activity being slightly lower than tannin sorghum cookies (Chiremba et al. 2009). Biscuits made of sorghum have been shown to reduce oxidative stress and inflammation and improve the glycemic response in people. It is an ideal alternative snack for people with obesity and diabetes (Stefoska-Needham et al. 2017).

\section{Potential animal feed additive}

Sorghum is a multipurpose crop and has a high demand as a fodder crop, especially in the kharif season. It also has great potential as an animal feed additive, which may improve animal health and production. Sorghum distillers' grain, an industrial by-product from the ethanol production unit, i a cheap material used as an additive in pig and rabbit fer $\mathrm{ds}$. It is rich in immune activators resulting from ferment fion. enhances immunity and improves animal health omeren. et al. 2010).

\section{Conclusion and future prospe ive}

Modern genetic engineering and $b$. In tools provide exciting opportunities to elop orghum with desirable nutritional and pheno. pro la wile maintaining good agronomic perform ance a vield. This could be a fruitful area for further 1 arch un, er rapidly changing climatic conditions. It has $b_{c}$ shown that through mutagenesisassisted b eeding, the bosynthesis of phenolic compounds can be ent ed ir sorghum. A sorghum mutagenesis variant $P$ for $D E N$, which can significantly increase the 2 ox anthocyanidins, condensed tannins, and total phenolh ontents in sorghum leaf, has been identified (Petti et al. 2,15 ). Advances have also been made in breeding sorghum (germplasms ATx3363 and BTx3363) with high levels of 3-deoxyanthocyanidins in the grain pericarp and satisfying grain yield (Dykes et al. 2013).

It may be concluded that various phenolic compounds from sorghum grain play a great role in overcoming biotic and abiotic stresses, such as insect pest attacks, drought, heat, and salinity. Additionally, sorghum brans can be used to fortify bread, cookies, and other snacks to improve their phytonutrient content, dietary fibers, and sensory properties, resulting in a positive effect on human health. A major limitation for their effect is their low bioavailability, which in turn depends on cultivars. Many researchers worldwide are working on a better understanding of the phenolic profile of sorghum and its specific role in overcoming biotic and abiotic stresses, which is an urgent need because of the everchanging climatic conditions. The focus must be ndir new extraction methods to increase their bioavaila ty $1 \mathrm{n}$ plants and humans. Sorghum, currently 2 sumed in seveloping and underdeveloped countries out on tay it will be preferred in developed countries a so due to it high bioactive compound concentration wh is having a beneficial impact on both plant and hur

Author contribution state. nt $\mathrm{PK}, \mathrm{RK}$ and SKP conceived and designed the manusc theme. PK and VK wrote the manuscrip Alt uthors read, edited and approved the manuscript.

Acknowledgenen.s The Authors would like to thank Dr. Nisha Thakur, Assistant Professor (English), Himachal Pradesh University, D. ' India, and Falcon Scientific Editing (https://falconediting.com) for $\mathrm{p}_{\mathrm{s}}$ freading the English language in this paper.

\section{D. clarations}

Conflict of interest The authors declare that they have no conflict of interest.

Human participants and/or animals Research did not involve human and/or animal subjects.

Informed consent All authors have read and approved the submission of this work.

\section{References}

Abdel-Aal ESM, Choo TM, Dhillon S, Rabalski I (2012) Free and bound phenolic acids and total phenolics in black, blue, and yellow barley and their contribution to free radical scavenging capacity. Cereal Chem 89:198-204. https://doi.org/10.1094/ CCHEM-10-11-0116

Afify AEMMR, El-Beltagi HS, El-Salam SMA, Omran AA (2012) Effect of soaking, cooking, germination and fermentation processing on proximate analysis and mineral content of three white sorghum varieties (Sorghum bicolor L. moench). Not Bot Horti Agrobot Cluj-Napoca 40:92-98. https://doi.org/10.15835/nbha4 027930

Anderson JW (2003) Whole grains protect against atherosclerotic cardiovascular disease. Proc Nutr Soc 62:135-142. https://doi.org/ 10.1079/pns2002222

Anderson A, Lindell CA, Moxcey KM et al (2013) Bird damage to select fruit crops: the cost of damage and the benefits of control 
in five states. Crop Prot 52:103-109. https://doi.org/10.1016/j. cropro.2013.05.019

Audilakshmi S, Stenhouse JW, Reddy TP, Prasad MVR (1999) Grain mould resistance and associated characters of sorghum genotypes. Euphytica 107:91-103. https://doi.org/10.1023/A:10264 10913896

Awika JM, Rooney LW, Waniska RD (2004) Properties of 3-deoxyanthocyanins from sorghum. J Agric Food Chem 52:4388-4394. https://doi.org/10.1021/jf049653f

Awika JM, Yang L, Browning JD, Faraj A (2009) Comparative antioxidant, antiproliferative and phase II enzyme inducing potential of sorghum (Sorghum bicolor) varieties. LWT-Food Sci Technol 42:1041-1046

Awika J (2000) Sorghum phenols as antioxidants. Doctoral dissertation, Texas A\&M University

Barcelos CA, Maeda RN, Santa Anna LMM, Pereira N (2016) Sweet sorghum as a whole-crop feedstock for ethanol production. Biomass Bioenerg 94:46-56. https://doi.org/10.1016/j.biombioe. 2016.08.012

Barros F, Awika JM, Rooney LW (2012) Interaction of tannins and other sorghum phenolic compounds with starch and effects on in vitro starch digestibility. J Agric Food Chem 60:11609-11617. https://doi.org/10.1021/jf3034539

Barros LAC, Cardoso De Aguiar HJA, Mariano CDSF, et al (2013) Cytogenetic characterization of the ant Trachymyrmex fuscus Emery, 1934 (Formicidae: Myrmicinae: Attini) with the description of a chromosomal polymorphism. In: Annales de la Societe Entomologique de France. Taylor \& Francis, pp 367-373

Basavaraju P, Shetty NP, Shetty SH et al (2009) Infection biology and defence responses in sorghum against lletotrichum sublineolum. J Appl Microbiol 107:404-415. https://doi.org/10.1111/j.13652672.2009.04234.x

Beecher GR (2004) Proanthocyanidins: biological activities associated with human health. Pharm Biol 42:2-20. https://doi.org/10.1 13880200490893474

Belton PS, Delgadillo I, Halford NG, Shewry PR (2006) Kafírin ture and functionality. J Cereal Sci 44:272-286. ht os://doi. 10.1016/j.jcs.2006.05.004

Betsiashvili M, Ahern KR, Jander G (2015) Additive effe of two quantitative trait loci that confer Rhopal siphum maid. (corn leaf aphid) resistance in maize inbred ine Mo17. J Exp Bot 66:571-578. https://doi.org/10.1093/jxb u379

Bralley E, Greenspan P, Hargrove JL, Hartle of hyaluronidase activity by sele ohum brans. J Med Food 11:307-312. https://doi.org/10.109/1 07.547

Bröhan M, Jerkovic V, Collip 2011) otentiality of red sorghum for producing stilben id-en ched $\mathrm{b}$-ers with high antioxidant activity. J Agric Food J88-4094. https://doi.org/10. $1021 /$ jf 1047755

Cabral JS, Whittale Wiegan. K, Kreft H (2019) Assessing predicted isolation et from the general dynamic model of island biogec raphy with a cco-evolutionary model for plants. J Biogeo. 16: 569-1581. https://doi.org/10.1111/jbi.13603

Chakraborth, Kum: i P, Pahuja SK et al (2020) Elucidation of com2. ng ab and fodder potential of sorghum hybrids. Forage $R_{f}$ 46:132-140

Cha ary w, Kumar V, Sangwan P et al (2021) Personalized nutrition omics. Compr Foodomics. https://doi.org/10.1016/B978-008-100596-5.22880-1

Cheng WN, Lei JX, Rooney WL et al (2013) High basal defense gene expression determines sorghum resistance to the whorl-feeding insect southwestern corn borer. Insect Sci 20:307-317. https:// doi.org/10.1111/1744-7917.12002

Chiremba C, Taylor JRN, Duodu KG (2009) Phenolic content, antioxidant activity, and consumer acceptability of sorghum cookies. Cereal Chem 86:590-594. https://doi.org/10.1094/ CCHEM-86-5-0590

Chong J, Poutaraud A, Hugueney P (2009) Metabolism and roles of stilbenes in plants. Plant Sci 177:143-155

Dai J, Mumper RJ (2010) Plant phenolics: extraction, analysis and their antioxidant and anticancer properties. Molecules 15:7313-7352. https://doi.org/10.3390/molecules 15107313

De Mey Y, Demont M, Diagne M (2012) Estimating bird damage to rice in Africa: evidence from the senegal river valley. J Agric Econ 63:175-200. https://doi.org/10.1111/j.1477-9552.2011. 00323.x

de Morais CL, Pinheiro SS, Martino HSD, Pinheiro- t'A a HM (2017) Sorghum (Sorghum bicolor L.): nutrients, bioa ve cor A- $^{-}$ pounds, and potential impact on human heálth. Crit K. ood Sci Nutr 57:372-390

Dempsey DA, Vlot AC, Wildermuth MC, K1 sig acid biosynthesis and metabolism Arab B 9:eb 0 . https://doi. org/10.1199/tab.0156

Deng Y, Lu S (2017) Biosynthesis / nd re ation o/ phenylpropanoids in plants. CRC Crit Rev Pla 1080/07352689.2017.1 402852

Devi PS, Kumar MS, Da S (2011) E aluation of antiproliferative activity of red Sorshum anthocyanin on a human breast cancer cell lin 'CF-7). h. Breast Cancer 2011:1-6. https:// doi.org/10 T61/2 11/891481

Dicko MH, Grupp pounds and rel. enzymes in sorghum varieties for resistance and ntibility to biotic and abiotic stresses. J Chem Ecol 31:26 7 1-_ nttps://doi.org/10.1007/s10886-005-7619-5

Dixon RA, ג ie DY, Sharma SB (2005) Proanthocyanidins-A final frontier $/$ flavonoid research? New Phytol 165:9-28. https://doi. $\mathrm{rg} / 10.1111 / \mathrm{j} .1469-8137.2004 .01217 . \mathrm{x}$

Dreyc DL, Jones KC (1981) Feeding deterrency of flavonoids and elated phenolics towards Schizaphis graminum and Myzus persicae: aphid feeding deterrents in wheat. Phytochemistry 20:2489-2493. https://doi.org/10.1016/0031-9422(81)83078-6

Dykes L (2019) Sorghum phytochemicals and their potential impact on human health. Methods Mol Biol 1931:121-140. https://doi. org/10.1007/978-1-4939-9039-9_9

Dykes L, Rooney LW (2006) Sorghum and millet phenols and antioxidants. J Cereal Sci 44:236-251. https://doi.org/10.1016/j.jcs. 2006.06.007

Dykes L, Peterson GC, Rooney WL, Rooney LW (2011) Flavonoid composition of lemon-yellow sorghum genotypes. Food Chem 128:173-179. https://doi.org/10.1016/j.foodchem.2011.03.020

Dykes L, Rooney WL, Rooney LW (2013) Evaluation of phenolics and antioxidant activity of black sorghum hybrids. J Cereal Sci 58:278-283. https://doi.org/10.1016/j.jcs.2013.06.006

Eastin JD, Lee K-W (2020) Sorghum bicolor. CRC handbook of flowering. Springer, CRC Press, pp 367-375

Eigenbrode SD, Espelie KE (1995) Effects of plant epicuticular lipids on insect herbivores. Annu Rev Entomol 40:171-194. https://doi. org/10.1146/annurev.en.40.010195.001131

Esele JP (1993) The association of genes controlling caryopsis traits with grain mold resistance in Sorghum. Phytopathology 83:490. https://doi.org/10.1094/phyto-83-490

Floegel A, Kim DO, Chung SJ et al (2010) Development and validation of an algorithm to establish a total antioxidant capacity database of the US diet. Int J Food Sci Nutr 61:600-623. https://doi.org/ $10.3109 / 09637481003670816$

Garzón AG, Torres RL, Drago SR (2019) Changes in phenolics, $\gamma$-aminobutyric acid content and antioxidant, antihypertensive and hypoglycaemic properties during ale white sorghum (Sorghum bicolor (L.) Moench) brewing process. Int J Food Sci Technol 54:1901-1908. https://doi.org/10.1111/ijfs.14102 
Genzeng R, Jianghui C, Xiaodong X et al (2019) Flavonoid biosynthesis pathway participating in salt resistance in a landrace sweet Sorghum revealed by RNA-sequencing comparison with grain Sorghum. J Agric Sci 11:63. https://doi.org/10.5539/jas.v11n6 p63

Girard AL, Awika JM (2018) Sorghum polyphenols and other bioactive components as functional and health promoting food ingredients. J Cereal Sci 84:112-124. https://doi.org/10.1016/j.jcs.2018.10. 009

Girard AL, Teferra T, Awika JM (2019) Effects of condensed vs hydrolysable tannins on gluten film strength and stability. Food Hydrocoll 89:36-43. https://doi.org/10.1016/j.foodhyd.2018.10.018

González-Montilla FM, Chávez-Santoscoy RA, Gutiérrez-Uribe JA, Serna-Saldivar SO (2012) Isolation and identification of phase II enzyme inductors obtained from black Shawaya sorghum [Sorghum bicolor (L.) Moench] bran. J Cereal Sci 55:126-131

Greenberg AS, Obin MS (2006) Obesity and the role of adipose tissue in inflammation and metabolism. Am J Clin Nutr 83:461S-465S. https://doi.org/10.1093/ajcn/83.2.461s

Gregor MF, Hotamisligil GS (2011) Inflammatory mechanisms in obesity. Annu Rev Immunol 29:415-445. https://doi.org/10.1146/ annurev-immunol-031210-101322

Hoi JT, Weller CL, Schlegel VL et al (2009) Sorghum distillers dried grain lipid extract increases cholesterol excretion and decreases plasma and liver cholesterol concentration in hamsters. J Funct Foods 1:381-386. https://doi.org/10.1016/j.jff.2009.09.005

Hole AS, Grimmer S, Jensen MR, Sahlstrøm S (2012) Synergistic and suppressive effects of dietary phenolic acids and other phytochemicals from cereal extracts on nuclear factor kappa B activity. Food Chem 133:969-977. https://doi.org/10.1016/j.foodchem. 2012.02.017

Ibraheem F, Gaffoor I, Chopra S (2010) Flavonoid phytoalexin-dependent resistance to anthracnose leaf blight requires a functionar yellow seed1 in Sorghum bicolor. Genetics 184:915-926. htt doi.org/10.1534/genetics.109.111831

Jideani AI, Silungwe H, Takalani T et al (2014) Antioxidan. natural grain products and human health. In: Ogur ibeju O Antioxidant-antidiabetic agents hum heal. InTe Croat, pp 167-187

Kam J, Puranik S, Yadav R et al (2016) Dietary interventions i type 2 diabetes: How millet comes to help. ront Plant Sci 7:1454. https://doi.org/10.3389/fpls.2016.01454

Kamath VG, Chandrashekar A, Rajini PS (200 nt: adical properties of sorghum (Sorghum bicol Moench) flour extracts. J Cereal Sci 40:283-288. https://doi.prg/4 /6/j.jcs.2004.08.004

Kariyat RR, Smith JD, Stepher AG et al (2017) Non-glandular trichomes of solanum c oline se dete feeding by manduca sexta caterpillars and cause gut peritrophic matrix. Proc R Soc B Biol S $1284: 20$ 323. https://doi.org/10.1098/rspb. 2016.2323

Kayodé APP, Nout MJ innemann AR et al (2011) Uncommonly high le vels of 3-deo anthocyanidins and antioxidant capacity he 'eaf sheaths of dye sorghum. J Agric Food Chem 59:11, 184

Kil s. eng L shimire BK et al (2009) Antioxidant and antimicrobi activities of crude sorghum extract. Food Chem 115:12342Jy. ....ps://doi.org/10.1016/j.foodchem.2009.01.032

Kim $r_{k}$ N (2012) Development and application of STEAM teachin model based on the Rube Goldberg's invention. In: Yeo S-S, Pan Y, Lee YS, Chang HB (eds) Lecture notes in electrical engineering. Springer, Dordrecht, pp 693-698

Klopfenstein T, Owen FG (1981) Value and potential use of crop residues and by-products in dairy rations. J Dairy Sci 64:1250-1268. https://doi.org/10.3168/jds.S0022-0302(81)82699-9

Kruger J, Taylor JRN, Du X et al (2013) Effect of phytate reduction of sorghum, through genetic modification, on iron and zinc availability as assessed by an in vitro dialysability bioaccessibility assay, Caco-2 cell uptake assay, and suckling rat pup absorption model. Food Chem 141:1019-1025. https://doi.org/ 10.1016/j.foodchem.2013.01.105

Kumar N, Goel N (2019) Phenolic acids: natural versatile molecules with promising therapeutic applications. Biotechnol Rep 24:370

Kumari P, Pahuja SK, Arya S, Patil JV (2016) Sorghum. In: Singh M, Kumar S (eds) Broadening the genetic base of grain cereals. Springer, New Delhi, pp 163-203

Kumari P, Pahuja SK, Sheoran RS et al (2017) Effect of varying levels of salinity on growth, yield and quality of forage sor num genotypes. Forage Res 43:64-66

Laxmi V, Pahuja SK, Kumari P (2019) Identification of $\mathrm{m}$ sourc s for good quality high biomass yield and other promisi raits in mini core collection of forage Sorghun dian J P an Genet Resour 32:150-157

Lee H, Peirsman Y, Chang A, et al (2011' Standford's ati-pass sieve coreference resolution system at $\mathrm{t}$ CoNLL-2011. In: Fifteenth conference on computational atur. nguag learning. Association for Computational Ling

Lee SM, Pan BS (2003) Inhi story efh of tannin in dietary sorghum distillery residue ar a liminary, eatment with polyethylene glycol on in vitro digestru $v$ of grey mullet (mugil cephalus). J Food Biochen 185-500. ps://doi.org/10.1111/j.1745-4514. 2003.tb005 6.x

Lewis JB, Tadde S nough CM et al (2008) Sorghum bran varieties differe lly influence endogenous antioxidant enzymes to pr against oxidative stress during colon carcinogenesis. Faseb ${ }_{2} \%$. 7

Links MR, 1 Aylor J, Kruger MC, Taylor JRN (2015) Sorghum condensed 1 inins encapsulated in kafirin microparticles as a nutraeutical for inhibition of amylases during digestion to attenuate perglycaemia. J Funct Foods 12:55-63. https://doi.org/10. 016/j.jff.2014.11.003

Li G, Godwin ID (2012) Highly efficient sorghum transformation. Plant Cell Rep 31:999-1007. https://doi.org/10.1007/ s00299-011-1218-4

Loeh SCC, De Verdier K, Nicholson RL (1999) Accumulation of 3-deoxyanthocyanidin phytoalexins and resistance to Colletotrichum sublineolum in sorghum. Physiol Mol Plant Pathol 55:263-273. https://doi.org/10.1006/pmpp.1999.0231

Luckemeyer TJ, Miller RK, Kerth CR, Adhikari K (2016) Beef flavor attributes and consumer perception II. Meat Sci 112:114

Makoi JHJR, Belane AK, Chimphango SBM, Dakora FD (2010) Seed flavonoids and anthocyanins as markers of enhanced plant defence in nodulated cowpea (Vigna unguiculata L. Walp.). F Crop Res 118:21-27. https://doi.org/10.1016/j.fcr.2010.03.012

Mehmood S, Bashir A, Ahmad A et al (2008) Molecular characterization of regional sorghum bicolor varieties from Pakistan. Pakistan J Bot 40:2015-2021

Melake-Berhan A, Butler LG, Ejeta G, Menkir A (1996) Grain mold resistance and polyphenol accumulation in Sorghum. J Agric Food Chem 44:2428-2434. https://doi.org/10.1021/jf950580x

Meng C, Zhang S, Deng Y-S et al (2015) Overexpression of a tomato flavanone 3-hydroxylase-like protein gene improves chilling tolerance in tobacco. Plant Physiol Biochem 96:388-400

Mkandawire NL, Kaufman RC, Bean SR et al (2013) Effects of sorghum (Sorghum bicolor (L.) Moench) tannins on $\alpha$-amylase activity and in vitro digestibility of starch in raw and processed flours. J Agric Food Chem 61:4448-4454. https://doi.org/10. $1021 / \mathrm{j} f 400464 \mathrm{j}$

Mokrane H, Amoura H, Belhaneche-Bensemra N et al (2010) Assessment of Algerian sorghum protein quality [Sorghum bicolor (L.) Moench] using amino acid analysis and in vitro pepsin digestibility. Food Chem 121:719-723. https://doi.org/10.1016/j.foodc hem.2010.01.020 
Moraes ÉA, Natal DIG, Queiroz VAV et al (2012) Sorghum genotype may reduce low-grade inflammatory response and oxidative stress and maintains jejunum morphology of rats fed a hyperlipidic diet. Food Res Int 49:553-559. https://doi.org/10.1016/j. foodres.2012.07.029

Mote UN, Shahane AK (1993) Studies on varietal reaction of sorghum to Delphacid, aphid and leaf sugary exudation. Indian J Entomol 55:360

Muriu JI, Njoka-Njiru EN, Tuitoek JK, Nanua JN (2002) Evaluation of sorghum (Sorghum bicolor) as replacent for maize in the diet of growing rabbits (Oryctolagus cuniculus). AsianAustralas J Anim Sci 15:565-569. https://doi.org/10.5713/ajas. 2002.565

Musa EM, Elsheikh EAE, Ahmed IAM, Babiker EE (2011) Effect of intercropping with cowpea (Vigna unuiculata L.), Bradyrhizobium inoculation and fertilization on physical and biochemical quality of sorghum (Sorghum bicolor L.) seeds. Electron J Environ Agric Food Chem 10:3064-3075

N'Dri D, Mazzeo T, Zaupa M et al (2013) Effect of cooking on the total antioxidant capacity and phenolic profile of some wholemeal African cereals. J Sci Food Agric 93:29-36. https://doi. org/10.1002/jsfa.5837

Nida H, Girma G, Mekonen M et al (2021) Genome-wide association analysis reveals seed protein loci as determinants of variations in grain mold resistance in sorghum. Theor Appl Genet 134:1167-1184. https://doi.org/10.1007/s00122-020-03762-2

Ofosu FK, Elahi F, Daliri EBM et al (2021) UHPLC-ESI-QTOF-MS/ MS characterization, antioxidant and antidiabetic properties of sorghum grains. Food Chem 337:127788. https://doi.org/10. 1016/j.foodchem.2020.127788

Ogurtsova K, da Rocha Fernandes JD, Huang Y et al (2017) IDF diabetes atlas: global estimates for the prevalence of diabetes for 2015 and 2040. Diabetes Res Clin Pract 128:40-50. https:/ doi.org/10.1016/j.diabres.2017.03.024

Petti C, Hirano K, Stork J, DeBolt S (2015) Mapping of a cel los deficient mutant named dwarf1-1 in Sorghum bicolor green revolution gene gibberellin20-oxidase reve is a posi regulatory association between gibberellin an 40 lose bio synthesis. Plant Physiol 169:705-716. https //abi.ors 1104/ pp. 15.00928

Pomerenke JL, Souza LWO, Shurson GC (2 10) Concentrations of $\beta$-glucans and mannan oligosaccharid in corn ried distillers grains with soluble (DDGS) and its nship to fiber components. J Anim Sci 93:206

Reinisalo M, Kårlund A, Koskela A et ar s) Polyphenol stilbenes: molecular mech ms or defence against oxidative stress and aging-rel ted seases Oxid Med Cell Longev. https://doi.org/10 1, 0 . 20

Salazar-López NJ, Gr nzâlez-A `lar G, Rouzaud-Sández O, RoblesSánchez M 20 Technoly gies applied to sorghum (Sorghum bicolor 1 meench, hanges in phenolic compounds and antioxidar capacity. Fo d Sci Technol 38:369-382. https://doi. org/ 15 ' $/$ fst 16017

Sánchez-Zà E, I uda-Martos M, Fernández-LÓpez J, Pérezarez 2015) Resistant starch as functional ingredient. Po rsaccharides Bioactivity Biotechnol 43:1911-1931. https:// O1.0ro.10.1007/978-3-319-16298-0_34

Saura- 'izto F, Pérez-Jiménez J, Touriño S et al (2010) Proanthocyanidin metabolites associated with dietary fibre from in vitro colonic fermentation and proanthocyanidin metabolites in human plasma. Mol Nutr Food Res 54:939-946. https://doi. org/10.1002/mnfr.200900276

Seneviratne G, Jayasinghearachchi HS (2003) Phenolic acids: Possible agents of modifying $\mathrm{N} 2$-fixing symbiosis through rhizobial alteration? Plant Soil 252:385-395
Sharma HC (1993) Host-plant resistance to insects in sorghum and its role in integrated pest management. Crop Prot 12:11-34. https://doi.org/10.1016/0261-2194(93)90015-B

Sharma S, Verslues PE (2010) Mechanisms independent of abscisic acid (ABA) or proline feedback have a predominant role in transcriptional regulation of proline metabolism during low water potential and stress recovery. Plant Cell Environ 33:1838-1851. https://doi.org/10.1111/j.1365-3040.2010. 02188.x

Sharma A, Shahzad B, Rehman A et al (2019) Response of phenylpropanoid pathway and the role of polyphenols in riants under abiotic stress. Molecules 24:2452

Singh V, Moreau RA, Hicks KB (2003) Yield and phytos 11 cor position of oil extracted from grain sorghurn and its we. Mled fractions. Cereal Chem 80:126-129. hto '/doi.org'10.1094/ CCHEM.2003.80.2.126

Stefoska-Needham A, Beck EJ, John on SK et a -017) A diet enriched with red sorghum flake biscuits, compared to a diet containing white wheat flak d bi its, do s not enhance the effectiveness of an energy-r ictea plan in overweight and mildly obese adul S. J Am Nutr 36:184-192. https:// doi.org/10.1080/070, 24.2016., 37314

Takabe T, Rai V, Hibino T (2u Metabolic engineering of glycine betaine. In: R K, Takab / (eds) Abiotic stress tolerance in plants. Spr ger, ordrecht, pp 137-151

Taleon V, Dykes type and envin nent on flavonoid concentration and profile of bl orghum grains. J Cereal Sci 56:470-475. https://doi. org/1C.10 jes.2012.05.001

Tipton KW, loydEH, Marshall JG, McDevitt JB (1970) Resistance of certa 1 grain sorghum hybrids to bird damage in Louisiana Agron J 62:211-213. https://doi.org/10.2134/agronj1970. $021962006200020010 x$

oiz mana F, Djami-Tchatchou AT, Steenkamp PA et al (2019) Metabolomic analysis of defense-related reprogramming in Sorghum bicolor in response to Colletotrichum sublineolum infection reveals a functional metabolic web of phenylpropanoid and flavonoid pathways. Front Plant Sci 9:1840

Vyas P, Singh D, Singh N et al (2018) Nutrigenomics: advances, opportunities and challenges in understanding the nutrientgene interactions. Curr Nutr Food Sci 14:104-115. https://doi. org/10.2174/1573401313666170614094410

Walling LL (2008) Avoiding effective defenses: Strategies employed by phloem-feeding insects. Plant Physiol 146:859-866. https:// doi.org/10.1104/pp.107.113142

Wani ZA, Ashraf N, Mohiuddin T, Riyaz-Ul-Hassan S (2015) Plantendophyte symbiosis, an ecological perspective. Appl Microbiol Biotechnol 99:2955-2965

Wedick NM, Ma Y, Olendzki BC et al (2015) Access to healthy food stores modifies effect of a dietary intervention. Am J Prev Med 48:309-317. https://doi.org/10.1016/j.amepre.2014.08.020

Weir TL, Park SW, Vivanco JM (2004) Biochemical and physiological mechanisms mediated by allelochemicals. Curr Opin Plant Biol 7:472-479. https://doi.org/10.1016/j.pbi.2004.05.007

Williams RJ, Rao KN (1981) A review of sorghum grain moulds. Trop Pest Manag 27:200-211. https://doi.org/10.1080/09670 878109413652

Xie Q, Xu Z (2019) Sustainable agriculture: from sweet sorghum planting and ensiling to ruminant feeding. Mol Plant 12:603606. https://doi.org/10.1016/j.molp.2019.04.001

Xiong Y, Zhang P, Warner RD, Fang Z (2019) Sorghum grain: from genotype, nutrition, and phenolic profile to its health benefits and food applications. Compr Rev Food Sci Food Saf 18:20252046. https://doi.org/10.1111/1541-4337.12506 
Xiong Y, Teixeira TV, Zhang P, Warner RD, Shen S, Fang Z (2021) Cellular antioxidant activities of phenolic extracts from five sorghum grain genotypes. Food Biosci 41:101068

Yang L, Browning JD, Awika JM (2009) Sorghum 3-deoxyanthocyanins possess strong phase II enzyme inducer activity and cancer cell growth inhibition properties. J Agric Food Chem 57:1797-1804. https://doi.org/10.1021/jf8035066

Young WR, Teetes GL (1977) Sorghum entomology. Annu Rev Entomol 22:193-218
Publisher's Note Springer Nature remains neutral with regard to jurisdictional claims in published maps and institutional affiliations.

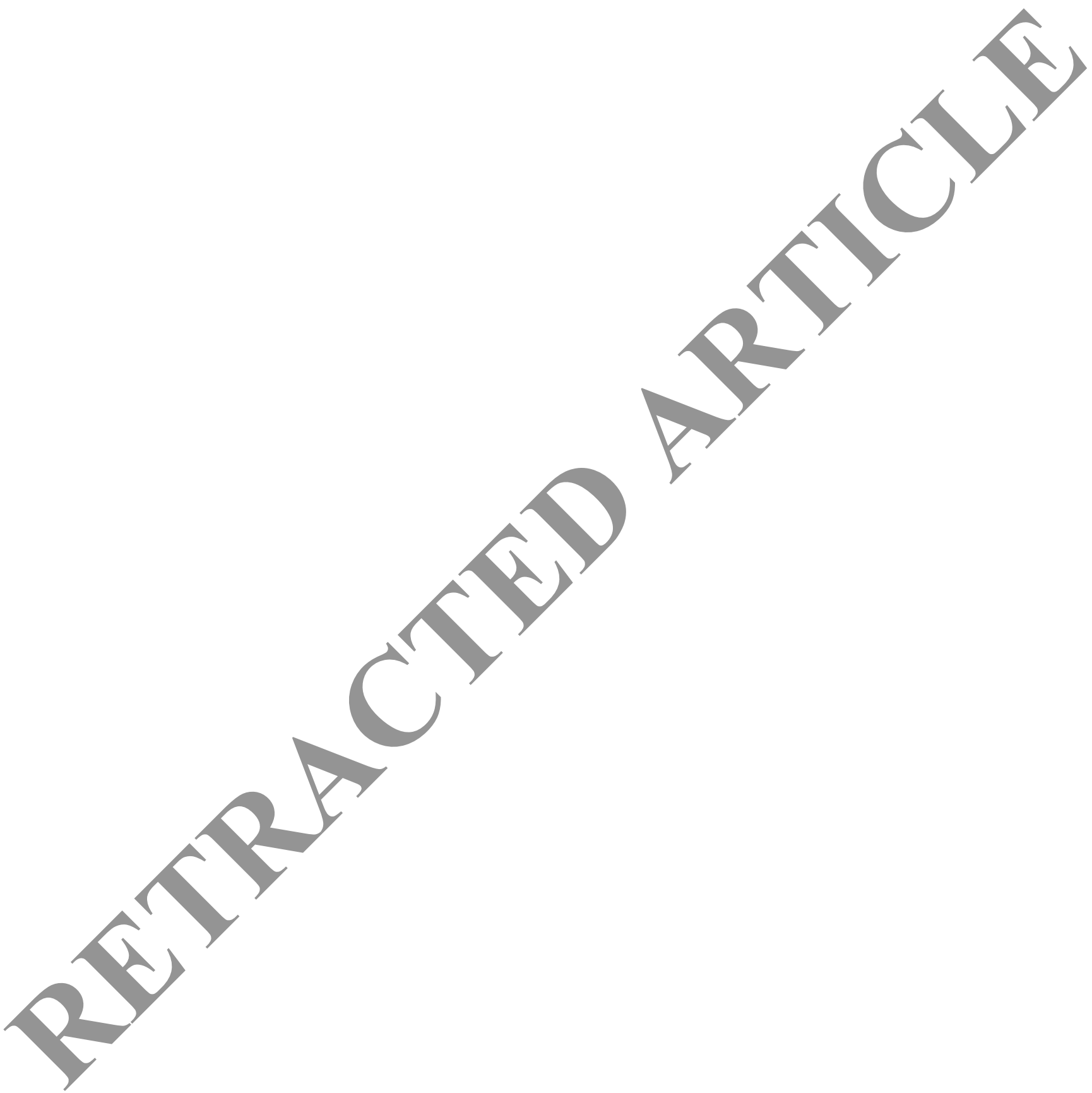

